\title{
Abductive Reasoning and Second Language Learning*
}

\author{
Ana S. Jovanovic \\ Faculty of Philology and Arts, University of Kragujevac, Kragujevac, Serbia \\ Email: anajovano@gmail.com \\ Gorana G. Zecevic Krneta \\ Faculty of Philology and Arts, University of Kragujevac, Kragujevac, Serbia \\ Email: goxiz@yahoo.com
}

\begin{abstract}
Although much work has been conducted on deductive and inductive approaches to second language learning, insufficient attention has been dedicated to abductive reasoning. This paper presents the results from an exploratory study on the processes that motivate initial hypothesis-making and their possible repercussions for $\mathrm{L} 2$ instruction. More specifically, the beginner foreign language learners' ability to infer word meaning based on their overall linguistic knowledge (e.g., knowledge of the first language, knowledge of other foreign languages) was tested in order to draw conclusions about abductive reasoning in L2 learning.
\end{abstract}

Index Terms - abductive reasoning, language acquisition, vocabulary acquisition, cross-linguistic influence

\section{INTRODUCTION}

Pierce $(1992,1998)$ described the scientific method as involving three phases: abduction that represents the process of making conjectures as to the hypotheses, deduction as the process of deriving consequences from these hypotheses, and induction through which we test these hypotheses. It is argued here that the same three modes of reasoning are present in the process of second language learning (L2). ${ }^{1}$ When a language learner is confronted with a new linguistic unit for the first time, he or she makes hypotheses about its meanings and possible functions. By means of deductive reasoning, the learner draws conclusions from the initial hypotheses about the possible contexts in which the given unit could be used. Finally, through the exposure to different examples within the given unit, he or she reinforces, modifies, or rejects the initial hypothesis. In other words, abduction could be described as a hunch that facilitates and speeds up language acquisition. However, as a non sequitur inference, it might also be responsible for a number of language errors. Consequently, this kind of reasoning needs to be recognized and directed in L2 instruction.

Although there is much work on deductive and inductive approaches to second language learning, insufficient attention has been dedicated to abductive reasoning. This paper presents the results from an exploratory study about the processes that motivate initial hypothesis-making and their possible repercussions for L2 instruction. More specifically, beginner foreign language learners' ability to infer word meaning based on their overall linguistic knowledge of the first and other foreign languages was tested.

In the following sections, the theoretical assumptions related to abductive reasoning and hypothesis-making in second language acquisition will be briefly exposed. Furthermore, concepts in relation to vocabulary acquisition are explored and the results from the word recognition test designed to probe beginner students' ability to infer word meaning based on their previous linguistic knowledge are presented. Finally, specific suggestions for future research are proposed, together with some recommendations for L2 instruction.

\section{ABDUCTION AND SECOND LANGUAGE LEARNING}

Prior to Peirce's work in the late $19^{\text {th }}$ century, logical arguments were traditionally divided into two subclasses: the class of deductive arguments, that is, necessary inference, and the class of inductive arguments or probable inference. However, Peirce extended this dichotomy to include abduction as a form of probable argument and he elaborated on it in a number of his philosophical writings from 1865 until 1914.

[A]bductive inference shades into perceptual judgment without any sharp line of demarcation between them; or in other words our first premises, the perceptual judgments, are to be regarded as an extreme case of abductive inferences, from which they differ in being absolutely beyond criticism. The abductive suggestion comes to us like a flash. It is an

\footnotetext{
* This study was completed as a part of the project number 178014 Dynamics of the structures of the modern Serbian language, which is financed by the Ministry of Education and Science of the Republic of Serbia.

${ }^{1} \mathrm{~A}$ distinction is frequently made between second vs. foreign language learning/acquisition. Second language acquisition generally refers to the acquisition of a language in the target country, while foreign language acquisition is seen as referring to a language learned outside of the target culture. Although the context of this study corresponds to the foreign language context, both terms are used interchangeably.
} 
act of insight, although of extremely fallible insight. It is true that different elements of the hypothesis were in our minds before; but it is the idea of putting together what we had never before dreamed of putting together which flashes the new suggestion before our contemplation. (Peirce 1998:227)

Abduction furnishes all our ideas concerning real things, beyond those given in perception, but is mere conjecture, without probative force. In the absence of any special reasons to the contrary, any hypothesis may be admissible. Burch (1998) explains that abduction is not always inference to the best explanation, but it is always inference to something that clarifies or makes routine some information that has previously been unexpected.

The mind seeks to bring the facts, as modified by the new discovery, into order; that is, to form a general conception, which can be done by an act of generalization. In other cases, no new law is suggested, but only a peculiar state of facts that explains the surprising phenomenon (Peirce, 1998: 287). When an already known rule is recognized as applicable to the suggested hypothesis, the phenomenon under the assumption would be quite likely or even a necessary result. This synthesis of previous knowledge and new insights, which suggest a new conception or hypothesis, represents abduction. It is neither more nor less than guessing (Peirce, 1998: 107).

It is proposed here that in the context of language learning (L1, L2, etc.), abduction represents a twofold process of perceiving specific language characteristics and making assumptions about their form and/or function. L2 learners already have considerable linguistic knowledge that can be highly productive on the condition that they know how to take advantage of this potential. Naturally, many variables are relevant in L2 learning, such as aptitude, personality, age, literacy, metalinguistic awareness, the use of strategies, knowledge of the world, and social background (Ellis, 1996: 472). They affect abduction in various ways and, at the same time, influence cross-linguistic inference.

Establishing the cross-linguistic influence (or transfer) is particularly relevant for the comprehension of a new language. Ringbom (2007: 15) proposes that "comprehension relies on three types of information: input (linguistics and other communicative), knowledge (linguistic and world knowledge), and context (linguistic and situational context)". He further distinguishes between "on-line comprehension" and "receptive learning". While on-line comprehension refers to the recognition and inference, receptive learning is consolidation and permanent storage of linguistic knowledge (Ringbom, 2007: 14). The first stage of encountering a new item in the learning process actually stands for abductive reasoning in L2 acquisition. It is operant in every aspect of language learning; however, the focus of this study is on the processes of L2 vocabulary on-line comprehension.

Laufer (1990: 574) conceives a word as a set of features (phonological, grammatical, semantic and distributional) and explains that every new word is incorporated into the total inventory of words stored in the learner's mind. Each learned word interacts with other words in the mental lexicon on the basis of semantic and phonological principles. Since words in L1 and L2/L3 are stored together in one lexicon, new words will interact with the semantically and phonologically related words both in the L1 and L2. In this study, these relationships are explored through a word recognition test that primarily takes into consideration formal similarities, as in the case of cognates. "Cognates in two languages can be defined as historically related, formally similar words, whose meanings may be identical, similar, partly different or, occasionally, even wholly different" (Ringbom, 2007: 73). Carroll (1992: 94) explains cognates in terms of a particular model of lexical activation and word recognition, defining them as lexical items from different languages that are identified by bilinguals as somehow being "the same thing". Thus, these underlying similarities of items are a concretely perceived similarity of a form and an associated, assumed similarity of function or meaning between source language and target language. In lexis, formal similarity to an existing L1 word is perceived first, in that getting the word form precedes getting the word meaning. Kirsner, Lalor and Hird (1993) make a point that learning cognates does not involve creating a new entry in memory, but rather adding new information to an existing entry. If formal correspondences can be observed, it leads a learner to a subsequent assumption of "associated translation equivalence" (see Ringbom 2007:9; Zimmermann, 1987). The extent to which these assumptions actually work determines whether the effect is positive or negative.

In the remainder of the study, results from the word recognition test are presented and interpreted in light of the exposed theoretical framework.

\section{METHODOLOGY}

\section{A. Test Description}

In order to establish the interaction of formal cross-linguistic influence and abductive reasoning, a word recognition test was designed. The test consisted of two sections: 1) two questions that inquired about the learners' language learning history, and 2) fifty words for which the learners were supposed to offer an adequate translation in their first language, i.e., Serbian. The purpose of the first section was to determine which languages the students were already familiar with and what language was the object of their academic career.

The second section of the test consisted of a list of fifty items given without the context, since the focal interest of this research was on-line vocabulary comprehension. The word recognition quiz examined the students' ability to infer a word meaning based solely on its form. The items for this section were chosen from the list of the most frequent Spanish words compiled by the Corpus Cumbre (Eduteka, 2005). In this way, we wanted to provide a criterion that would guarantee an approximate degree of familiarity with the items in the test, independently of their respective 
categories. That is to say, in order to explore the relationship between the inference strategies and the students' language learning histories, the fifty items from the test were categorized into six groups according to their forms:

1. The first group was made up of words considered to be Indo-European cognates, such as centro [center], clase [class], masa [mass], par [pair] etc.;

2. Cognates in Spanish and English, e.g., oficina [office], patata [potato], suburbio [suburb], etc.;

3. Spanish and French cognates, e.g., brazo [arm, Fr. bras], caballo [horse, Fr. cheval], guerra [war, Fr. guerre], etc.;

4. False cognates ${ }^{2}$ in Spanish and English, such as arma [weapon], carpeta [folder], nudo [knot], pariente [relative], pie [foot], etc.;

5. False cognates in Spanish and Serbian, such as cada [each] (Sr. /kada/, [bathtub]), nada [nothing] (Sr. /nada/, [hope]), regalo [gift] (Sr. /regal/ [closet]), voz [voice] (Sr. /voz/ [train]), etc. These words represent absolute or close homophones in Serbian and Spanish, although their meaning is not related in any way. To give an example, the word nada [nothing] is spelled and pronounced in the same way in both Spanish and Serbian /nada/, but its meaning in Serbian is hope;

6. The sixth category was conceived as a control group, that is, it consisted of items with no formal similarities with any of the previously mentioned languages: coche [car], iglesia [church], silla [chair], etc.

\section{B. Participants}

The participants of this study are first-year students of the Faculty of Foreign Languages and Literatures at the University of Kragujevac enrolled in the beginner level Spanish language course. They major in one of the following departments: Serbian language and literature, English language and literature, French language and literature, or German language and literature. The Department of Serbian language and literature is designed for competent speakers of the Serbian language; they have a foreign language requirement, so during their first year of the academic program they choose one of the foreign languages offered by the Faculty (English, Spanish, French, or German). The students are not required to have previous knowledge in any of these languages. On the contrary, students who enroll in one of the foreign language departments must pass the entrance exam, which consists of tests of both Serbian and a foreign language of choice. In addition to this foreign language, they also have a foreign language requirement for which they do not need any previous knowledge. Consequently, it is assumed that the students of the beginner Spanish language course do not have any knowledge of Spanish. However, their language learning histories differ importantly, which might influence essentially the way they approach the learning of the Spanish language.

In total, 79 students completed the test. There were 21 students from the Department of Serbian language, 40 students from the English department, 11 students from the Department of French, and only 7 from the German Department. After a preliminary analysis of the data, which did not show any significant difference between the students of French and German, these students were treated as one group so that a number of statistical procedures could be completed. The consequent analyses were completed with three groups: the students from the Department of Serbian language and literature (SL, $n=21)$, the students from the Department of English language and literature $(E L, n=40)$, and the students from the Departments of French and German languages (FGL, $n=18$ ).

\section{Goals}

The data were analyzed with several goals in mind. One goal was to determine the words for which the students offered correct translations, incorrect translation, or did not offer any translation. The proportion of correct, incorrect, and unanswered items among the participants as a whole was analyzed, as well as the type of error in the offered translations, with the object of explaining their origin. Finally, the existence of significant differences among the groups was determined.

\section{RESULTS}

In the data analysis, the type of answer that was categorized either as a correct translation, incorrect translation, or lack of response was investigated first. The analysis of variance showed that there was indeed a significant difference among these three types of responses, $\mathrm{F}(2,245)=397.2$, $\mathrm{p}<0.0001$ (see Fig.1). In fact, as much as $56 \%$ of all answers were correct, $16 \%$ of the translations were incorrect, and $28 \%$ of the items were left unanswered. These results show that, in spite of the low level of competence in the Spanish language, the students knew or were able to infer the correct meaning of many words in the test. This is not unexpected since most of the students did have some exposure to Spanish through television programming and/or music in the Spanish language. At the same time, it is probable that many of the correct translations were due to the appropriate use of abductive reasoning. Unfortunately, the test design did not allow the interpretation of the source of the correct answers, so the conclusions about abduction were essentially drawn from the error analysis.

${ }^{2}$ False cognates are "words that involve completely different meanings and referents although they involve identical or similar surface forms" (Lalor \& Kirnser, 2001:553). 


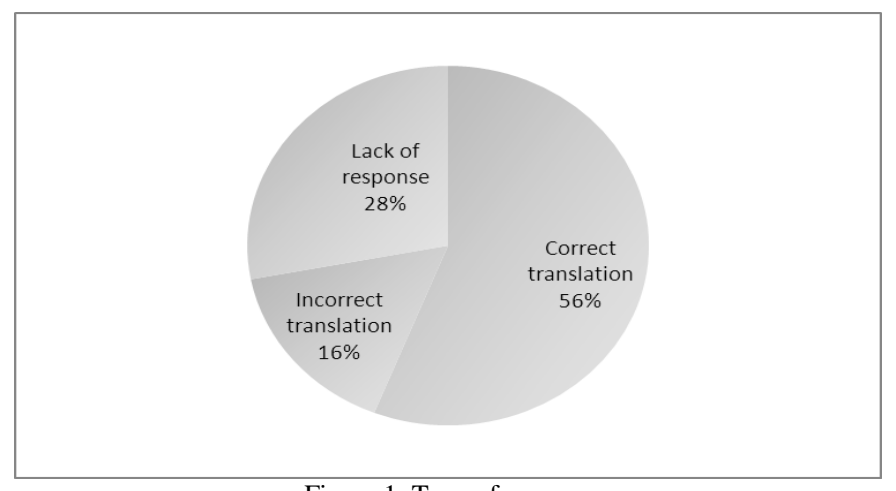

Figure 1. Type of answer.

In contrast, the lack of response may indicate the absence of abductive reasoning, which might be influenced by the type of the test. Although it was clarified that this word recognition test did not have any bearing on the course program or course evaluation, the students might have succumbed to the prevailing testing habits. In the traditional teaching context, incorrect answers are generally frowned upon, so the students are frequently apprehensive of giving responses that they are not completely sure of. If this is the case, it might have negative influence on the development of inference strategies and abductive reasoning in the L2 learning process, especially if we bear in mind that in abduction we seek not to avoid error but to generate hypotheses that have informational virtue (Levi, 1983: 41-50). ${ }^{3}$

As was previously mentioned, $16 \%$ of all responses were qualified as incorrect and these were the focal interest of further analyses, both quantitative and qualitative. The incorrect answers were coded for any association with the languages used by the participants, which enabled the creation of three categories of incorrect answers: 1) translations that can be connected with the English language (approximately 25\% of the incorrect answers); 2) translations that are somehow inspired by the Serbian language (approximately 23\%); and 3) incorrect responses that were provoked by other mechanisms beyond the scope of this study (approximately 51\%). Interestingly, we were not able to determine responses that implied association with the French language. The analysis of variance did not show significant statistical difference among the three types of responses, $\mathrm{F}(2,147)=2.522, \mathrm{p}=0.084$.

However, a more detailed analysis of specific word categories revealed some important findings. In the first place, it became clear that the students tend to infer word meaning from English when they identify a resemblance between this and the target language (see Table 1). This is an example of "foreign language effect", a tendency observed in language learners to rely on lexical influence from a non-native language (see Cenoz, 2001; Ringbom, 2007: 79). Apparently, learners look for whatever lexical and structural similarities they can perceive between the L2 and L3 if they consider the L2 and L3 to be related. In these instances, the foreign language effect may actually be stronger than L1 influence, which was confirmed by our data.

TABLE 1.

RESPONSES FOR THE ITEMS IN THE CATEGORIES OF SPANISH-ENGLISH COGNATES AND SPANISH-ENGLISH FALSE COGNATES

\begin{tabular}{|c|c|c|c|c|c|c|c|c|c|c|}
\hline & \multicolumn{5}{|c|}{ Spanish-English cognates } & \multicolumn{5}{|c|}{ Spanish-English false cognates } \\
\hline & $\begin{array}{c}\text { noticia } \\
\text { [notice] }\end{array}$ & $\begin{array}{l}\text { oficina } \\
\text { [office] }\end{array}$ & $\begin{array}{c}\text { patata } \\
\text { [potato] }\end{array}$ & $\begin{array}{c}\text { plato } \\
\text { [plate] }\end{array}$ & $\begin{array}{l}\text { suburbia } \\
\text { [suburb] }\end{array}$ & $\begin{array}{c}\text { arma } \\
\text { [weapon] }\end{array}$ & $\begin{array}{l}\text { carpeta } \\
\text { [folder] }\end{array}$ & $\begin{array}{c}\text { nudo } \\
\text { [knot] }\end{array}$ & $\begin{array}{l}\text { pariente } \\
\text { [relative] }\end{array}$ & $\begin{array}{c}\text { pie } \\
\text { [foot] }\end{array}$ \\
\hline $\begin{array}{l}\text { Correct } \\
\text { translation }\end{array}$ & 35 & 38 & 11 & 22 & 9 & 10 & 0 & 0 & 5 & 6 \\
\hline No response & 0 & 0 & 0 & 4 & 0 & 24 & 17 & 23 & 6 & 2 \\
\hline $\begin{array}{l}\text { Incorrect } \\
\text { translation }\end{array}$ & 2 & 1 & 24 & 11 & 28 & 4 & 21 & 14 & 19 & 29 \\
\hline $\begin{array}{l}\text { Association with } \\
\text { English }\end{array}$ & 35 & 38 & 11 & 23 & 9 & 24 & 14 & 23 & 6 & 2 \\
\hline
\end{tabular}

This strategy, which represents a form of abductive reasoning, clearly helps learners infer the correct word meaning in the case of Spanish and English cognates. However, it is also responsible for an important percentage of transfer errors. The analysis of variance showed that there is a statistically significant difference in the type of response in the case of Spanish-English false cognates, $F(5,44)=17.944, p<0.0001$. In fact, this is the most frequent source of error, as can be observed in Fig. 2, since as many as $91.08 \%$ of all translations of the Spanish-English false cognates were incorrect. While many cognates in the L2 provide useful pegs on which the learner can hang new L3 words, these deceptive cognates, which have a purely formal but little or no semantic similarity, are, as previously discussed, very problematic items that must be properly treated in foreign vocabulary acquisition.

\footnotetext{
${ }^{3}$ An argument possesses informational virtue if it suggests new phenomena or if it better explains those we already know about (for more on informational virtue, see Levi, 1983).
} 


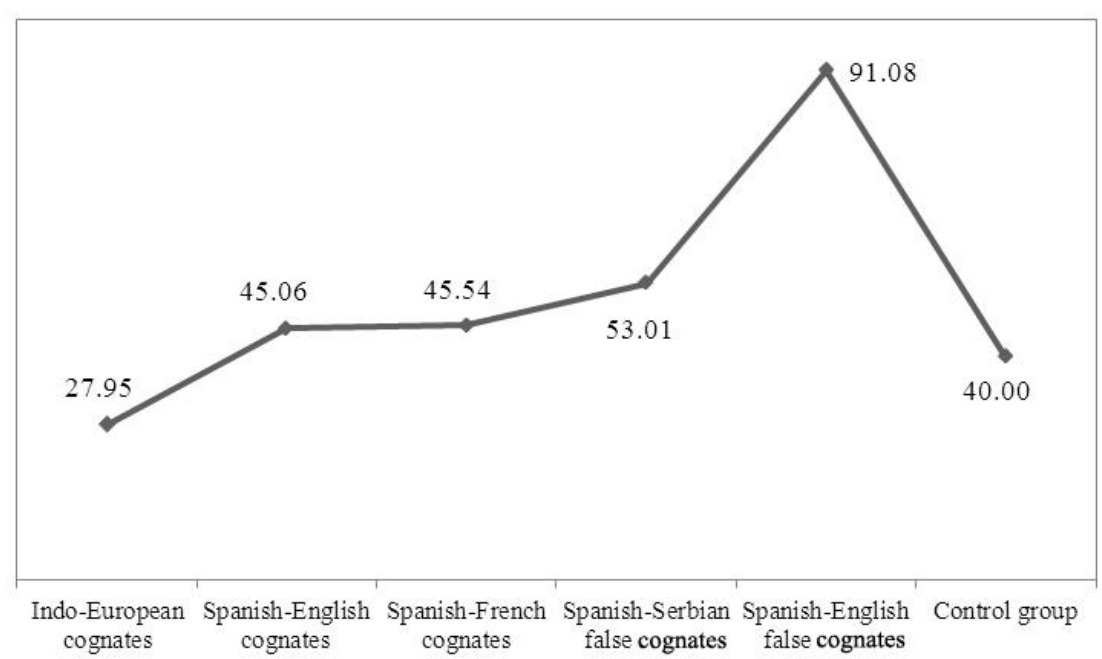

Figure 2. Incorrect responses across different word categories.

While the students relied strongly on the resemblance between the English and Spanish language at the time of word recognition, they seemed quite reluctant to associate the target language with their L1. This was obvious in the case of the Spanish-Serbian false cognates, as well as with certain Indo-European cognates. Thus, in the case of the SpanishSerbian false cognates, only $11 \%$ of incorrect responses were due to the association with the Serbian language, while as many as $30 \%$ were left unanswered (see Fig. 3 for more detail).

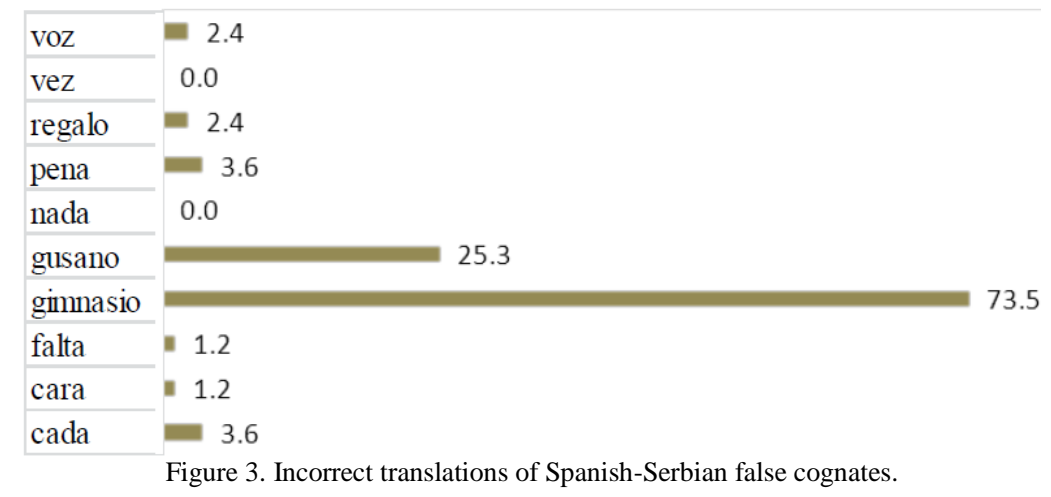

As can be observed, the major portion of mistakes is related to the word gimnasio [gym], which in fact represents an Indo-European cognate. However, it is also a false cognate since in Serbian the word of the same origin stands for high school. If we were to exclude this specific item from the list of the Spanish-Serbian cognates, only $4.64 \%$ of the mistakes in this word category could be explained by the association with the Serbian language. Naturally, it is beneficial not to make analogies between false cognates, since incorrect hypotheses are created in this way. Unfortunately, the lack of inference strategies is also evident in the case of true cognates, which is detrimental for the students' learning process (see Table 2). While a significant portion of translations were indeed correct (just above $75 \%$ of all responses), approximately $17 \%$ were left without any answer. It could be argued that the students' abductive reasoning made them infer correct meanings from the cognates. Still, it strikes us that in the case of some words a number of participants were particularly reluctant to use this strategy. Thus, while masa is both homophone and homograph in Spanish and Serbian, as many as 38 students did not offer any translation for this item. The results were similar for the words par [pair], sala [hall], and tema [theme], for which a straightforward association with the L1 would have brought them to correct responses.

TABLE 2.

RESPONSES FOR EACH OF THE ITEMS IN THE CATEGORY OF INDO-EUROPEAN COGNATES

\begin{tabular}{|l|c|c|c|c|c|c|c|c|c|c|}
\hline & centro & clase & familia & grupo & masa & paciente & par & programa & sala & tema \\
\hline $\begin{array}{l}\text { Correct } \\
\text { translation }\end{array}$ & 73 & 73 & 79 & 79 & 25 & 67 & 14 & 77 & 51 \\
\hline $\begin{array}{l}\text { Incorrect } \\
\text { translation }\end{array}$ & 2 & 2 & 0 & 0 & 16 & 11 & 20 & 0 & 5 \\
\hline No response & 4 & 4 & 0 & 0 & 38 & 1 & 45 & 2 & 23 & 19 \\
\hline
\end{tabular}


The qualitative analysis of specific erroneous answers showed interesting evidence of creative use of inference strategies. On several occasions, the participants offered the translation English woman (Sr. /engleskina/) for the word iglesia, which could be connected with the Spanish word inglés [English]. A similar process was operant in some translations of the word obra [work]. Among other responses, honor related to the Spanish honra, poor to pobre, and shadow to sombra were particularly illustrative. These represent errors caused by the perception of intralingual similarities.

Interlingual similarities, on the other hand, may also motivate negative transfer, as was observed in the following examples: the word carpeta [folder] was translated as rag due to the formal similarity with the Serbian word /krpa/; there were also several instances of translations of bottle for the Spanish boca [mouth] due to the Serbian /botsa/. These errors are provoked by the participants' perception of synforms, that is, similar lexical forms. This inference strategy tends to maintain consonant word structure while vowels seem to be of less importance, which is in line with Laufer (1997: 147).

In across-group comparison, the analysis of variance showed a significant difference in the case of the incorrect answers, while the differences were not statistically significant across any other comparison. More specifically, the students from the Department of Serbian language gave more incorrect translations when compared with the students of the foreign language departments, $\mathrm{F}(2,147)=3.087, \mathrm{p}<0.05$ (see Fig. 4). Further analysis showed that this difference came essentially from the greater percentage of mistakes in the case of Spanish and English cognates. The results imply that the students from the Department of Serbian language possess less knowledge of the English language than their colleagues from the foreign language departments, which is not surprising if the participants' language learning histories are considered. However, it is an additional argument for the inclusion of metacognitive training within the context of L2 instruction, particularly with the students who have scarce language learning experience.

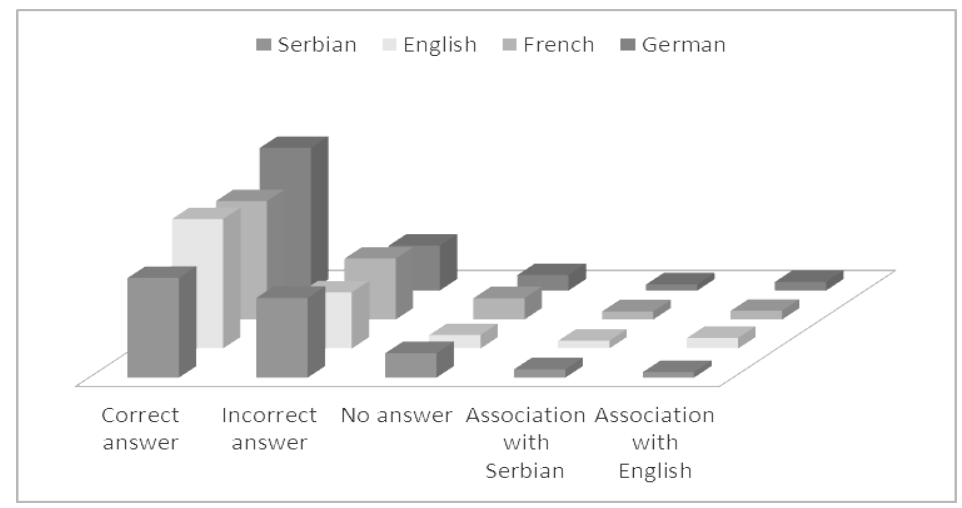

Figure 4. Differences across the groups.

\section{CONCLUSION}

The natural procedure in learning something new is to establish a connection between a new proposition and what already exists in the mind. Language learners, especially at early stages of learning, normally tend to establish a one-toone relationship with an item in another language. The quantitative results of the word recognition test showed that, in spite of their low level of competence in the Spanish language, the participants were able to translate a significant number of vocabulary items which might indicate their use of appropriate inference strategies. L2 learners generally assume that if a word in another language is formally similar to an L1 word, it will also have an identical or at least similar meaning. This perceptive judgment, along with a subsequent hypothesis of associated translation equivalence, reflects individuals' access to abductive processes. In this manner, transfer occurs not only from the L1, but also from other languages known to the student. In fact, if the L2 and L3 are related, but the L1 and L3 are not, learners look for whatever lexical and structural similarities they can identify between the L2 and L3. The data analysis has shown that the students strongly rely on their knowledge of English vocabulary, especially when they perceive a resemblance between English and Spanish. The influence of English as an L2 seems to be more productive than the influence of the L1, probably due to the students' expectations of English and Spanish relatedness.

An important finding of the study comes from the data that exhibit the participants' reluctance to formulate hypotheses on word meaning. This group of students tended not to venture a possible translation when they did not know the correct meaning of the word, although some resemblance could have been noticed. This lack of perceptive and assumed reasoning is possibly influenced by the instructional context, which still maintains values of the traditional model of education. Traditionally, the error has been perceived as evidence of the lack of knowledge and, as such, it has been disapproved. It is suggested here that certain errors actually reveal learning processes and, more specifically, abductive reasoning, through which new connections are perceived and comprehended. Consequently, errors should not be banned but rather used as important information about learners' cognitive processes. If teachers are aware of their students' difficulties in learning specific word items, they may adjust their teaching techniques for vocabulary 
presentation and practice. Additionally, more attention could be dedicated to false cognates (particularly between the L2 and L3), since they appear to be a frequent source of confusion for beginning learners. In this sense, proper explanation of differences in meaning, pragmatic and cultural use should be provided in order to enhance students' learning of cognates and their appropriate use. Finally, it is essential that at early stages of language learning, considerable effort be dedicated to the development and improvement of students' inference strategies. In learning, abduction is a moving force responsible for major leaps in judgment. It enables the establishment of new connections between the pieces of information that were previously perceived as unrelated. While this study looks at vocabulary on-line comprehension, it would be interesting to observe abductive processes in other realms of language use and their effect on specific language competences.

\section{APPENDIX A WORD RECOGNITION TEST}

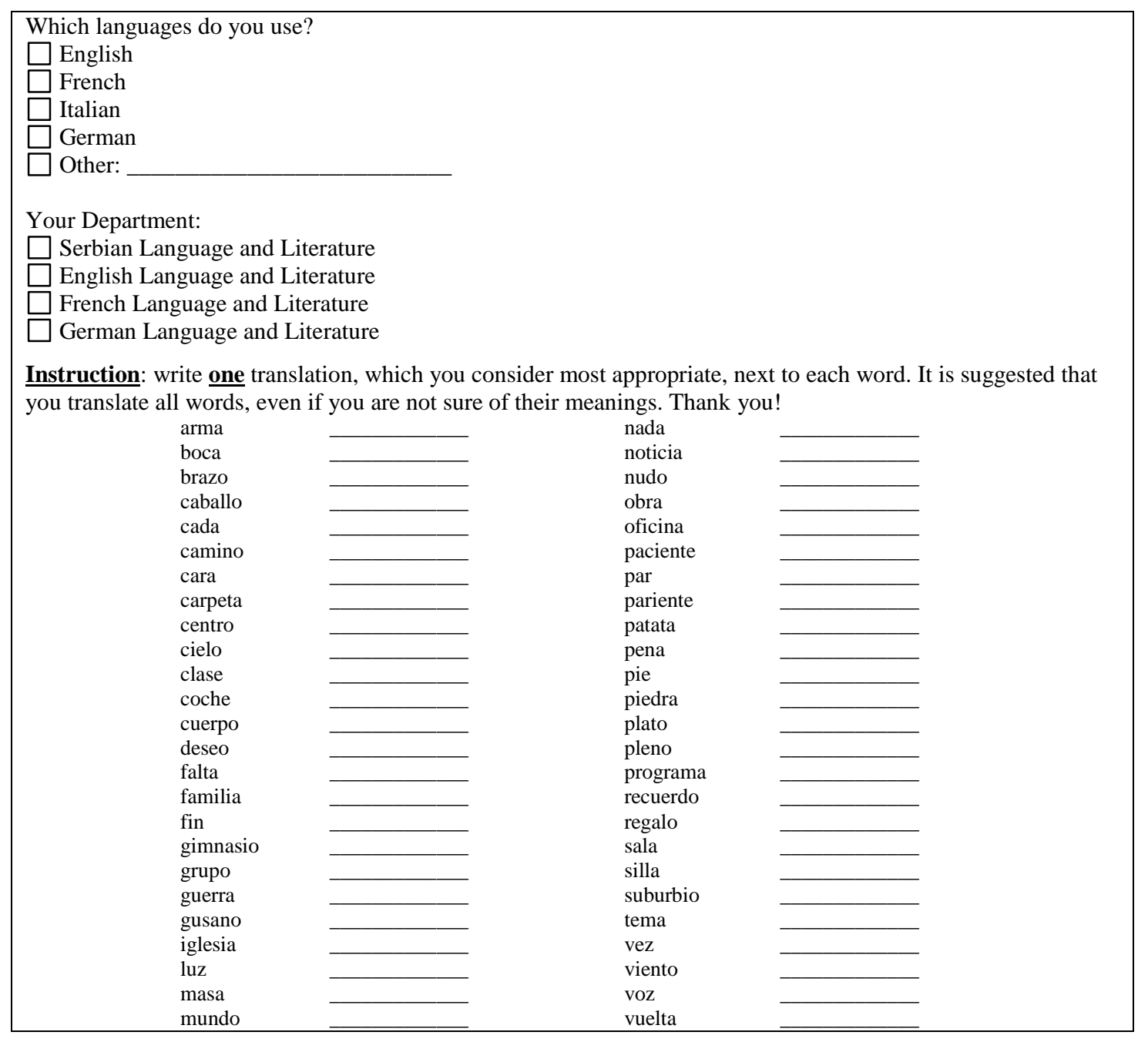

\section{REFERENCES}

[1] Burch, R. (2009). Charles Sanders Peirce. In Stanford encyclopedia of philosophy. http://plato.stanford.edu/entries/peirce/ (accessed 1/10/2011).

[2] Carroll, S. E. (1992). On cognates. Second Language Research 8.2, 93-119.

[3] Cenoz, J. (2001). The effect of linguistic distance, L2 status and age on cross-linguistic influence in third language acquisition. In J. Cenoz, B. Hufeisen \& U. Jessner (eds.), Cross-linguistic influence in third language acquisition. Clevedon: Multilingual Matters, 8-20.

[4] Cenoz, J., B. Hufeisen \& U. Jessner (eds.) (2001). Cross-linguistic influence in third language acquisition. Clevedon: Multilingual Matters.

[5] Eduteka. (2005). Listado de palabras utilizadas con mayor frecuencia en castellano. Documento elaborado por EDUTEKA con información proveniente del Anexo 3 de R. Almela, P. Cantos, A. Sánchez, R. Sarmiento \& M. Almela, Frecuencias del español. Diccionario y estudios léxicos y morfológicos (http://www.um.es/lacell/proyectos/dfe/). Editorial Universitas, S.A. http://www.eduteka.org/curriculo2/TecladoPalabrasFrecuentes.pdf (accessed 1/10/2011).

[6] Ellis, R. (1996). The study of second language acquisition. Oxford: Oxford University Press. 
[7] Fisiak, J. (ed.) (1990). Further insights in contrastive linguistics. Amsterdam: John Benjamins.

[8] Kirsner, K., E. Lalor \& K. Hird. (1993). The bilingual lexicon: Exercise, meaning and morphology. In R. Schreuder \& B. Weltens (eds.), The bilingual lexicon. Amsterdam: John Benjamins, 215-246.

[9] Lalor, E. \& K. Kirsner. (2001). The representation of "false cognates" in the bilingual lexicon. Psychonomic Bulletin \& Review $8.3,552-559$.

[10] Laufer, B. (1990). Words you know: How they affect the words you learn. In J. Fisiak (ed.), Further insights in contrastive linguistics. Amsterdam: John Benjamins, 573-593.

[11] Levi, I. (1983). The enterprise of knowledge. An essay on knowledge, credal probability, and chance. Cambridge, MA: MIT Press.

[12] Pierce, C. S. (1992, 1998). The essential Peirce (2 vols.). Edited by N. Houser, C. Kloesel \& the Peirce Edition Project. Bloomington, IN: Indiana University Press.

[13] Rigbom, H. (2007). Cross-linguistic similarity in foreign language learning. Clevedon-Buffalo-Toronto: Multilingual Matters.

[14] Schreuder, R. \& B. Weltens (eds.) (1993). The bilingual lexicon. Amsterdam: John Benjamins.

[15] Zimmermann, R. (1987). Form-oriented and content-oriented lexical errors in L2 learners. International Review of Applied Linguistics 25, 55-67.

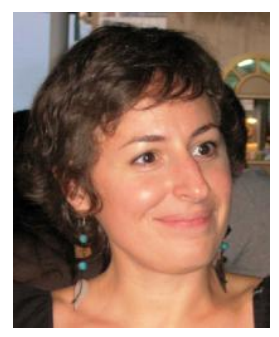

Ana S. Jovanovic (Belgrade, 1977) graduated at the Department of Iberic Studies, Faculty of Philology at the University of Belgrade in Serbia. She pursued Master's and doctoral studies at the Department of Foreign Languages and Literatures at Purdue University, USA, where she received a Ph.D. degree in Spanish Applied Linguistics in 2008 .

She is currently an Assistant Professor of Applied Linguistics and the Spanish language at the University of Kragujevac, Faculty of Philology and Arts, Serbia. She teaches courses related to teacher training and SLA. Her primary research interests are in the interdisciplinary approach to issues related to individual differences and classroom dynamics in L2 learning, as explored in her recent publication Student and teacher attitudes in foreign language instruction (Belgrade, Serbia: Andrejevic Endowment, 2009).

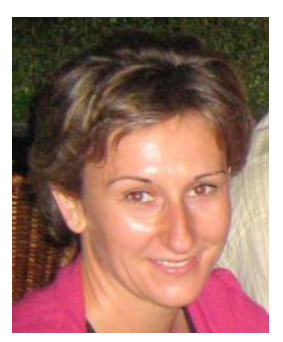

Gorana G. Zecevic Krneta (Sarajevo, 1978) received a bachelor's degree in Spanish Language and Literature from the Faculty of Philology at the University of Belgrade, Serbia, in 2001. She is Ph.D. candidate in Linguistics at the Faculty of Philology and Arts at the University of Kragujevac (Serbia), and she has begun her Ph.D. thesis titled The use of the definite article in Spanish as a foreign language based on error analysis in the written production of Serbian Spanish learners at the university level.

Since March 2003 she is a Spanish Language Teaching Assistant at the Faculty of Philology and Arts, University of Kragujevac (Serbia), where she teaches courses related to the methodology of teaching Spanish as a foreign language, contrastive analysis and Spanish syntax. Her primary research interests focus on second language development and how insights from cognitive and contrastive linguistics can help improve language teaching. At the same time, she is conducting research on the Judeo-Spanish language. Finally, she has written various articles on the above mentioned topics.

Ms. Zecevic Krneta obtained an accesit at the $44^{\text {th }}$ Concourse of the Association of the Jewish Communities of Yugoslavia, Belgrade, November 2000, for the research paper "Fifteen Judeo-Spanish Poems from Sarajevo and Thessaloniki: Phonetic and Phonological Analysis", written in cooperation with Ana Stulic and Ivana Vucina. 